\title{
${ }^{1} \mathrm{H}$ and ${ }^{13} \mathrm{C}$ NMR Assignments of Cytotoxic $3 S$-1,2,3,4-Tetrahydro- $\beta$-carboline-3-carboxylic Acid from the Leaves of Cichorium endivia
}

\author{
Fu-Xin Wang, An-Jun Deng, Jin-Feng Wei, Hai-Lin Qin, and Ai-Ping Wang \\ Institute of Materia Medica, Chinese Academy of Medical Sciences and Peking Union Medical College, Beijing 100050, China \\ Correspondence should be addressed to Hai-Lin Qin, qinhailin@imm.ac.cn and Ai-Ping Wang, wangaiping@imm.ac.cn
}

Received 17 September 2012; Accepted 26 November 2012

Academic Editor: Feng Wei

Copyright ( $) 2012$ Fu-Xin Wang et al. This is an open access article distributed under the Creative Commons Attribution License, which permits unrestricted use, distribution, and reproduction in any medium, provided the original work is properly cited.

\begin{abstract}
An amino acid, 3S-1,2,3,4-tetrahydro- $\beta$-carboline-3-carboxylic acid, was isolated for the first time from the leaves of Cichorium endivia. The complete assignment of its ${ }^{1} \mathrm{H}$ and ${ }^{13} \mathrm{C}$ NMR spectroscopic data was carried out also for the first time based on extensive 1D and 2D NMR experiments. Cytotoxicity of this isolated compound against HCT-8 and HepG2 human cancer cell lines was evaluated for the first time, with moderate activities being found.
\end{abstract}

\section{Introduction}

Cichorium endivia $\mathrm{L}$. is a popular vegetable from the family of Compositae and is widely cultivated and consumed all over the world. Its popularity is also attributed to the healthy properties mainly due to supply of antioxidant activity $[1,2]$. However, phytochemical investigation on this plant is very rare up to now, to the best of our knowledge, only a few papers had reported a few compounds, including five ones by our group [3]. The ongoing research aims at confirming the bioactive compounds from this popular vegetable, and a prevailing and known amino acid, 3S-1,2,3,4-tetrahydro$\beta$-carboline-3-carboxylic acid (1), was isolated for the first time. By way of the literature survey, it can be learned that the complete assignment of the NMR data of 1 was very deficient up to now, with no practical conducting being obtained due to the poor solubility of $\mathbf{1}$ in most prevalent solvents and causing the citation of literatures an obvious state of chaos $[4,5]$. In this paper, we describe the complete assignment of the ${ }^{1} \mathrm{H}$ and ${ }^{13} \mathrm{C}$ NMR spectroscopic data of 1 based on the determining of optimized solvent and extensive $1 \mathrm{D}$ and 2D NMR experiments. An investigation focusing on the cytotoxicity of compound 1 against HCT- 8 and HepG2 human cancer cell lines showed that $\mathbf{1}$ inhibits the cells growth by a moderate reduction in viability of subjects.

\section{Results and Discussion}

Compound 1 was isolated as an amorphous pale-yellow pow$\operatorname{der}\left(\mathrm{MeOH} / \mathrm{H}_{2} \mathrm{O}\right)$. Its positive-ion ESI-MS spectrum showed the quasimolecular ion peaks at $\mathrm{m} / \mathrm{z} 217.1[\mathrm{M}+\mathrm{H}]^{+}$and 239.1 $[\mathrm{M}+\mathrm{Na}]^{+}$, and its molecular formula was established to be $\mathrm{C}_{12} \mathrm{H}_{12} \mathrm{~N}_{2} \mathrm{O}_{2}$ by the quasimolecular ion peak in the positive mode HRESI-MS experiment at $\mathrm{m} / \mathrm{z} 217.0967[\mathrm{M}+\mathrm{H}]^{+}$. The IR spectrum showed strong absorptions at $v_{\max } 3284$, $3019,1642,1598,1452,1409$, and $740 \mathrm{~cm}^{-1}$, indicating the presence of 1,2-disubstitued benzene moiety and labile hydrogen. It was preliminarily identified as $3 S-1,2,3,4-$ tetrahydro- $\beta$-carboline-3-carboxylic acid by comparison of the ${ }^{1} \mathrm{H}$ NMR spectroscopic data obtained in DMSO- $\mathrm{d}_{6}$ with the literature values $[4,5]$, but some obvious errors or inconsistency were evident, including the coupling constants and data ownership (Table 1). Whereas the obtainment of ${ }^{13} \mathrm{C}$ NMR spectrum in the NMR solvent of DMSO- $\mathrm{d}_{6}$ was very difficult due to the above-mentioned poor solubility, compound 1 was then recorded the 1D and 2D NMR spectra within $\mathrm{D}_{2} \mathrm{O}+$ drops of $\mathrm{F}_{3} \mathrm{CCOOD}$, which proved to be a good solvent for 1 . The ${ }^{1} \mathrm{H}$ NMR spectroscopic data also clearly revealed the existence of 1,2-disubstitued benzene moiety, with four diagnostic signals from an aromatic $\mathrm{ABCD}$ spin system resonating at $\delta_{\mathrm{H}} 7.13(1 \mathrm{H}, \mathrm{t}, J=7.6 \mathrm{~Hz}, \mathrm{H}-6)$, 
TABLE $1:{ }^{1} \mathrm{H}$ and ${ }^{13} \mathrm{C}$ NMR spectroscopic data for compound $\mathbf{1}$.

\begin{tabular}{|c|c|c|c|c|c|c|}
\hline Number & $\delta_{\mathrm{H}}^{\mathrm{ab}}$ & $\delta_{\mathrm{C}}{ }^{\mathrm{ac}}$ & $\delta_{\mathrm{H}}^{\mathrm{de}}$ & $\delta_{\mathrm{H}}{ }^{\mathrm{d}}[4]$ & $\delta_{\mathrm{H}}^{\mathrm{d}}[5]$ & $\delta_{C}{ }^{\mathrm{d}}[5]$ \\
\hline $1 \mathrm{a}$ & $4.38 \mathrm{~d}(15.6)$ & $40.5 \mathrm{t}$ & $4.15 \mathrm{~d}(15.3)$ & - & - & 40.3 \\
\hline $1 b$ & $4.54 \mathrm{~d}(15.6)$ & & $4.23 \mathrm{~d}(15.9)$ & $4.22 \mathrm{~d}(4.8)$ & - & \\
\hline 3 & $4.27 \mathrm{dd}(10.4,5.6)$ & $55.0 \mathrm{~d}$ & $3.60 \mathrm{~m}$ & 3.14 & - & 55.3 \\
\hline $4 \mathrm{a}$ & $3.13 \mathrm{dd}(10.8,16.4)$ & $21.7 \mathrm{t}$ & $2.81 \mathrm{dd}-$ like & $2.83 \mathrm{ddd}(10.5,5.0,2.4)$ & - & 18.0 \\
\hline $4 \mathrm{~b}$ & $3.38 \mathrm{dd}(5.6,16.4)$ & & 3.13 br d-like & $3.69 \mathrm{dd}(10.5,5.0)$ & - & \\
\hline $4 a^{\prime}$ & & $104.9 \mathrm{~s}$ & & & & 104.3 \\
\hline $4 b^{\prime}$ & & $125.6^{\mathrm{f}} \mathrm{s}$ & & & & 128.5 \\
\hline 5 & $7.53 \mathrm{~d}(8.0)$ & $118.2 \mathrm{~d}$ & $7.32 \mathrm{~d}(7.5)$ & $7.33 \mathrm{~d}(8.0)$ & $7.38 \mathrm{~d}(8.2)$ & 118.5 \\
\hline 6 & $7.13 \mathrm{t}(7.6)$ & $120.0 \mathrm{~d}$ & $7.06 \mathrm{t}(7.5)$ & $7.08 \mathrm{t}(8.0)$ & $7.06 \mathrm{t}(8.2)$ & 117.5 \\
\hline 7 & $7.22 \mathrm{t}(8.0)$ & $122.9 \mathrm{~d}$ & $6.97 \mathrm{t}(7.8)$ & $6.99 \mathrm{t}(7.5)$ & $6.96 \mathrm{t}(8.2)$ & 121.1 \\
\hline 8 & $7.43 \mathrm{~d}(8.0)$ & $111.9 \mathrm{~d}$ & $7.43 \mathrm{~d}(7.5)$ & $7.44 \mathrm{~d}(7.5)$ & $7.44 \mathrm{~d}(8.2)$ & 111.8 \\
\hline $8 \mathrm{a}$ & & $136.7 \mathrm{~s}$ & & & & 136.1 \\
\hline $9 \mathrm{a}$ & & $125.4^{\mathrm{f}} \mathrm{s}$ & & & & - \\
\hline $\mathrm{COOH}$ & & $171.3 \mathrm{~s}$ & $10.91 \mathrm{~s}$ & $10.93 \mathrm{~s}$ & - & 165.6 \\
\hline 9-NH & & & & - & $10.66 \mathrm{~s}$ & \\
\hline
\end{tabular}

${ }^{\mathrm{a}} \mathrm{D}_{2} \mathrm{O}+$ drops of $\mathrm{F}_{3} \mathrm{CCOOD}$; ${ }^{\mathrm{b}} 400 \mathrm{MHz} .{ }^{\mathrm{c}} 100 \mathrm{MHz} .{ }^{\mathrm{d}}$ in DMSO- $\mathrm{d}_{6}$; ${ }^{\mathrm{e}} 300 \mathrm{MHz} .{ }^{\mathrm{f}}$ Assignments may be interchanged.

$7.22(1 \mathrm{H}, \mathrm{t}, J=8.0 \mathrm{~Hz}, \mathrm{H}-7), 7.43(1 \mathrm{H}, \mathrm{d}, J=8.0 \mathrm{~Hz}, \mathrm{H}-8)$, and $7.53(1 \mathrm{H}, \mathrm{d}, J=8.0 \mathrm{~Hz}, \mathrm{H}-5)$, which correlated to the aromatic carbon signals at $\delta_{\mathrm{C}} 120.0(\mathrm{C}-6), 122.9(\mathrm{C}-7), 111.9$ (C-8), and 118.2 (C-5), respectively, in the HSQC spectrum. In addition, five well-resolved and characteristic signals at $\delta_{\mathrm{H}}$ $4.38\left(1 \mathrm{H}, \mathrm{d}, J=15.6 \mathrm{~Hz}, \mathrm{H}-1_{a}\right), 4.54(1 \mathrm{H}, \mathrm{d}, J=15.6 \mathrm{~Hz}$, $\left.\mathrm{H}-1_{b}\right), 4.27(1 \mathrm{H}, \mathrm{dd}, J=10.4,5.6 \mathrm{~Hz}, \mathrm{H}-3), 3.13(1 \mathrm{H}, \mathrm{dd}$, $\left.J=10.8,16.4 \mathrm{~Hz}, \mathrm{H}-4_{a}\right)$, and $3.38(1 \mathrm{H}, \mathrm{dd}, J=5.6,16.4 \mathrm{~Hz}$, $\mathrm{H}-4_{b}$ ) were also examined in the ${ }^{1} \mathrm{H}$ NMR spectrum, which were, conveniently according to their coupling constants and with the aid of ${ }^{1} \mathrm{H},{ }^{1} \mathrm{H}$-COSY spectrum, assigned to one $\mathrm{AB}$ spin system from an isolated methylene group and one $A B X$ system from one methylene and one methine correlated together by $s p^{3}$ hybridized bond. These three functional groups were obviously deshielded and were correlated to their corresponding carbon signals at $\delta_{\mathrm{C}} 40.5(\mathrm{C}-1), 55.0$ (C-3), and 21.7 (C-4), respectively, in the HSQC spectrum. Simply, these three groups were arranged to either $s p^{2}$ hybridized carbons or nitrogen atoms when considering the ${ }^{1} \mathrm{H}$ and ${ }^{13} \mathrm{C}$ NMR chemical shifts and examining the ${ }^{13} \mathrm{C}$ and DEPT NMR data which exhibited twelve carbon signals with two aliphatic methylenes, one aliphatic methine, four $s p^{2}$ hybridized methines, and five $s p^{2}$ hybridized quaternary carbons being categorized (Table 1). The above NMR data were compatible with a benzene moiety, a tetrasubstituted ethylene, and a carbonyl except for the above-mentioned three aliphatic carbons. The long range ${ }^{1} \mathrm{H},{ }^{13} \mathrm{C}$-correlations from $\delta_{\mathrm{H}} 7.53$ to $\delta_{\mathrm{C}} 104.9,125.6,136.7$, and 122.9 , from $\delta_{\mathrm{H}}$ 7.43 to $\delta_{\mathrm{C}} 122.9,120.0$, and 125.6, from $\delta_{\mathrm{H}} 7.22$ to $\delta_{\mathrm{C}} 111.9$, 136.7, and 118.2, from $\delta_{\mathrm{H}} 7.13$ to $\delta_{\mathrm{C}} 118.2,125.6,122.9$, and 111.9 , from $\delta_{\mathrm{H}} 4.38$ and 4.54 to $\delta_{\mathrm{C}} 125.4,104.9$, and 55.0, from $\delta_{\mathrm{H}} 3.13$ and 3.20 to $\delta_{\mathrm{C}} 104.9,55.0,171.3$, and $125.6 / 125.4$, and from $\delta_{\mathrm{H}} 4.27$ to $\delta_{\mathrm{C}} 171.3,40.5,21.7$, and
104.9 established the constitutional formula of $\mathbf{1}$ as indicated by Figure 1. The complete assignment of the NMR data is listed in Table 1.

On evaluation of compound $\mathbf{1}$ for its cytotoxic effects on two human cancer cell lines, cell growth was measured using a sulforhodamine B (SRB) assay. Results of means of three replicates are expressed as the percentage of viability compared to negative control. Compound 1 exhibited moderate cytotoxicities against HCT-8 and HepG2 cell-lines in the evaluation, with viability of HepG2 and HCT-8 cells being $80.42 \%$ and $80.22 \%$ after treatment for 48 hours, and $76.14 \%$ and $71.48 \%$ after 72 hours, respectively, when using a concentration of $140 \mu \mathrm{g} / \mathrm{mL}$. The viabilities at other time points were relatively lower.

\section{Experimental}

3.1. General Experimental Procedures. IR spectra were obtained on a Nicolet 5700 spectrometer. 1D and 2D NMR spectra were recorded on a Mercury-400 or a MERCURY-300 NMR spectrometer. Chemical shifts $(\delta)$ were given in ppm using tetramethylsilane (TMS) as internal standard $(\delta 0.00)$. ESI-MS and HRESI-MS were measured on an Agilent 1100 series LC-MSD-Trap-SL spectrometer. RP-18 (YMC-GEL, ODS-A, $12 \mathrm{~nm}, \mathrm{~S}-50 \mathrm{~mm}$; YMC Co., Kyoto, Japan) were used for column chromatography. Solvents were of analytical grade and were purchased from Beijing Chemical Company (Beijing, China).

3.2. Plant Material. Cichorium endivia was purchased from Beijing Xinfadi agricultural products wholesale market on July 2009 and authenticated by Associate Professor Ma Lin 

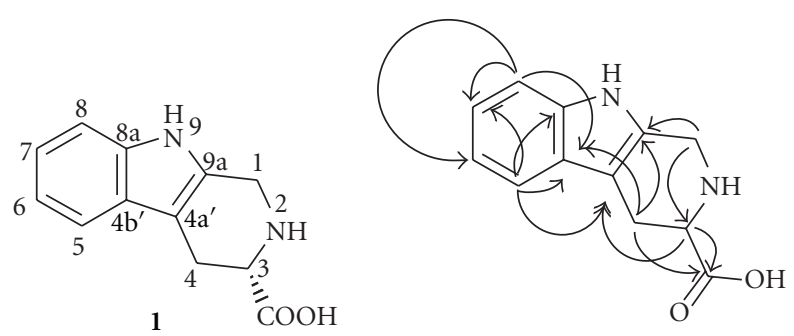

FIgure 1: The structure of compound 1 and the key $\operatorname{HMBC}(\rightarrow: H \rightarrow C)$ correlations.

(Institute of Material Medica, Chinese Academy of Medical Sciences and Peking Union Medical College). A voucher specimen was deposited in New Drug Safety Evaluation Center, Institute of Materia Medica, Peking Union Medical College \& Chinese Academy of Medical Sciences, China.

3.3. Extraction and Isolation. The air-dried and pulverized C. endivia $(5.8 \mathrm{~kg}$ ) was extracted three times under reflux conditions with 95\% EtOH ( $80 \mathrm{~L}, 2 \mathrm{~h} ; 70 \mathrm{~L}, 1 \mathrm{~h} ; 68 \mathrm{~L}, 1 \mathrm{~h})$. The combined EtOH extracts were evaporated in vacuum to yield a dark-green residue ( $1233 \mathrm{~g}$, crude EtOH extract), which was suspended in $80 \%$ aq. EtOH. The resulting suspension was extracted with petroleum ether $\left(60-90^{\circ} \mathrm{C}\right.$, $2 \mathrm{~L}, 1.5 \mathrm{~L}, 1.5 \mathrm{~L}$, and $1.5 \mathrm{~L}$ ). Evaporation of the aq. layers in vacuum yielded also a dark-green residue $(940 \mathrm{~g}, 80 \%$ $\mathrm{EtOH}$ extract). The residue was redissolved in water and subsequently partitioned with EtOAc in separatory funnel exhaustively. The rest of water soluble fraction was loaded on a column filled with Daion HP-20 and eluted with $\mathrm{H}_{2} \mathrm{O}$, $60 \% \mathrm{EtOH}$, and $95 \% \mathrm{EtOH}$, respectively. The eluates of $60 \%$ $\mathrm{EtOH}$ were evaporated in vacuum which yielded a black residue $(40 \mathrm{~g})$.

The $60 \% \mathrm{EtOH}$ fraction was redissolved in solvent of $n-\mathrm{BuOH}$ and washed with aq. $5 \% \mathrm{NaHCO}_{3}$ then $\mathrm{H}_{2} \mathrm{O}$, respectively. Evaporation of $n$ - $\mathrm{BuOH}$ under reduced pressure gave $5.5 \mathrm{~g}$ of brown-green residue, which was submitted to an ODS-A column eluted with $\mathrm{MeOH}-\mathrm{H}_{2} \mathrm{O}$ of decreasing polarity (40\%-100\%) to yield compound $\mathbf{1}(108 \mathrm{mg}$ ) as paleyellow powder.

3.3.1. 3S-1,2,3,4-Tetrahydro- $\beta$-carboline-3-carboxylic Acid(1). Pale-yellow powder. IR $(\mathrm{KBr}) v_{\max }\left(\mathrm{cm}^{-1}\right): 3284,3019$, $2849,1642,1598,1452,1409,1271,1221$, and $740 ;{ }^{1} \mathrm{H}$ and ${ }^{13} \mathrm{C}$ NMR spectroscopic data are listed in Table 1. ESIMS (positive mode) m/z: $217.1[\mathrm{M}+\mathrm{H}]^{+}$and $239.1[\mathrm{M}+\mathrm{Na}]^{+}$; HRESI-MS (positive mode) m/z: $217.0967[\mathrm{M}+\mathrm{H}]^{+}($calcd for $\mathrm{C}_{12} \mathrm{H}_{12} \mathrm{~N}_{2} \mathrm{O}_{2}$, 217.0972).

3.4. Cytotoxicity Assay. HCT-8 and HepG2 cells were cultivated in RPMI1640 medium containing $0.22 \%$ sodium bicarbonate, $10 \%$ fetal bovine serum (FBS), $100 \mathrm{U} / \mathrm{mL}$ penicillin, and $100 \mu \mathrm{g} / \mathrm{mL}$ streptomycin. The cells were incubated in $5 \%$ $\mathrm{CO}_{2}$-air at $37^{\circ} \mathrm{C}$. Compound $\mathbf{1}$ was dissolved in phosphatebuffered saline (PBS) at a concentration of $1.4 \mathrm{mg} / \mathrm{mL}$ and was diluted to the required concentration with RPMI1640 medium immediately before use.

The cell viability was measured by using sulforhodamine B (SRB) assay. Briefly, the cells were seeded in 96-well plates $\left(1 \times 10^{4}\right.$ cells/well $)$ and routinely cultured for $24 \mathrm{~h}$. Compound 1 was added to in-serial concentrations (from $14 \mu \mathrm{g} / \mathrm{mL}$ to $140 \mu \mathrm{g} / \mathrm{mL}$ ), while PBS was added alone to control wells as a negative control, and incubation was continued for an additional $48 \mathrm{~h}$. SRB $(1 \mathrm{mg} / \mathrm{mL})$ was added to each well after the plates were fixed using TCA $(0.4 \% \mathrm{~m} / \mathrm{v})$. After 20 minutes of incubation, each well was washed by acid $(1 \% \mathrm{v} / \mathrm{v})$ three times. Then wells were added into Tris $(100 \mathrm{mmol} / \mathrm{L})$, respectively. The absorbance of each well was recorded on a microplate spectrophotometer at $515 \mathrm{~nm}$.

\section{Acknowledgments}

The authors thank Associate Professor L. Ma for the sample authentication. The authors are also thankful to the State Key Laboratory of Bioactive Substance and Function of Natural Medicine and Drug Safety Evaluation Center, Institute of Materia Medica, for providing cells and equipment for research.

\section{References}

[1] M. S. DuPont, Z. Mondin, G. Williamson, and K. R. Price, "Effect of variety, processing, and storage on the flavonoid glycoside content and composition of lettuce endive," Journal of Agricultural and Food Chemistry, vol. 48, no. 9, pp. 3957-3964, 2000.

[2] R. Llorach, A. Martínez-Sánchez, F. A. Tomás-Barberán, M. I. Gil, and F. Ferreres, "Characterisation of polyphenols and antioxidant properties of five lettuce varieties and escarole," Food Chemistry, vol. 108, pp. 1028-1038, 2008.

[3] C. J. Chen, A. J. Deng, C. Liu, R. Shi, H. L. Qin, and A. P. Wang, "Hepatoprotective activity of Cichorium endivia L. extract and its chemical constituents," Molecules, vol. 16, pp. 9049-9066, 2011.

[4] J. P. Peng, Y. Q. Qiao, and X. S. Yao, "Nitrogen-containing compounds from Allium macrostmon Bunge. and Allium chinese G. Don," Chinese Journal of Medicinal Chemistry, vol. 5, p. 134, 1995.

[5] S. Yahara, N. Uda, E. Yoshio, and E. Yae, "Steroidal alkaloid glycosides from tomato (Lycopersicon esculentum)," Journal of Natural Products, vol. 67, no. 3, pp. 500-502, 2004. 


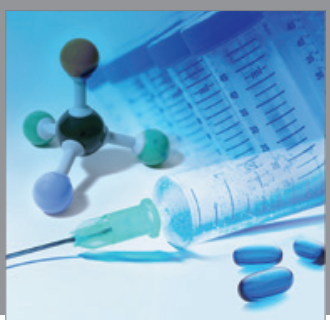

International Journal of

Medicinal Chemistry

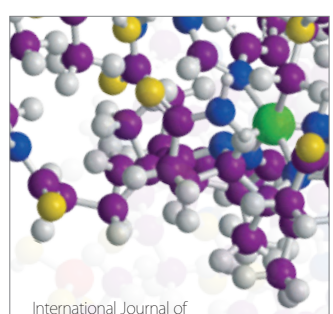

Carbohydrate Chemistry

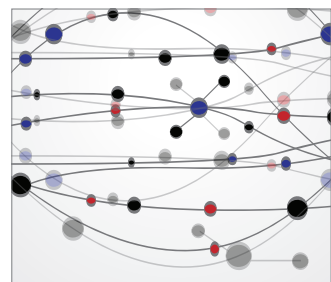

The Scientific World Journal
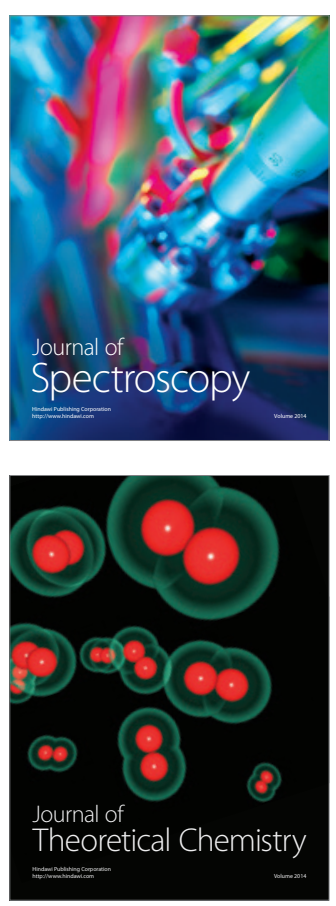
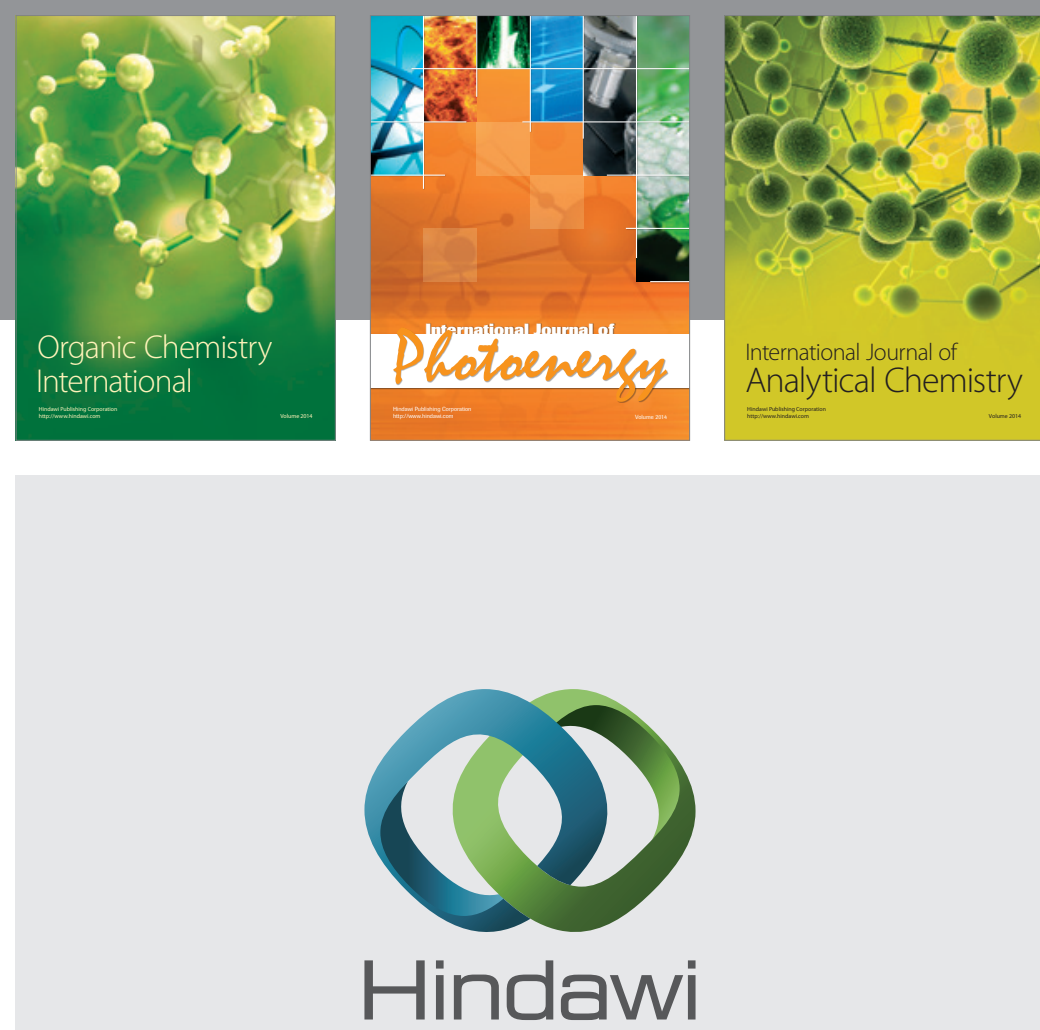

Submit your manuscripts at

http://www.hindawi.com
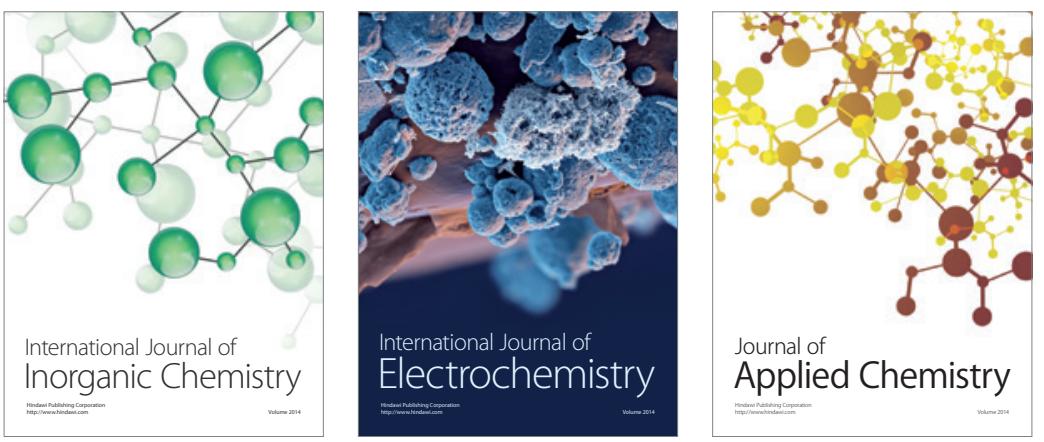

Journal of

Applied Chemistry
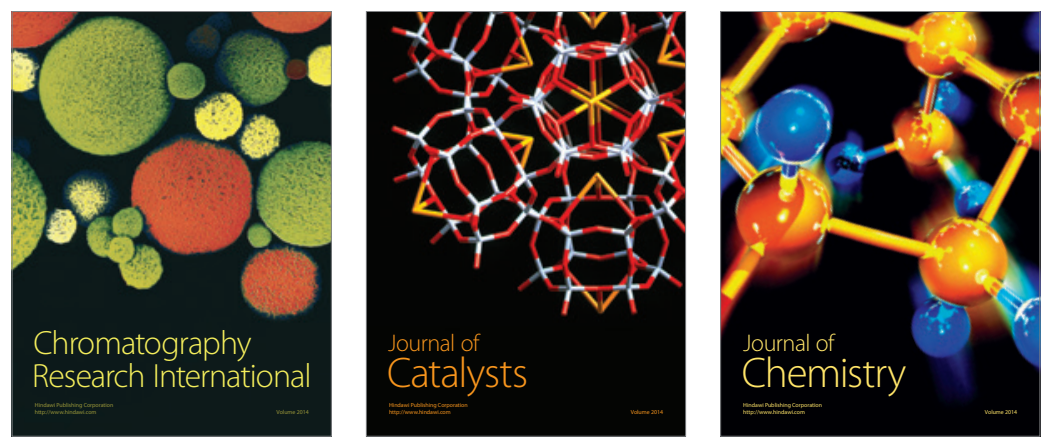
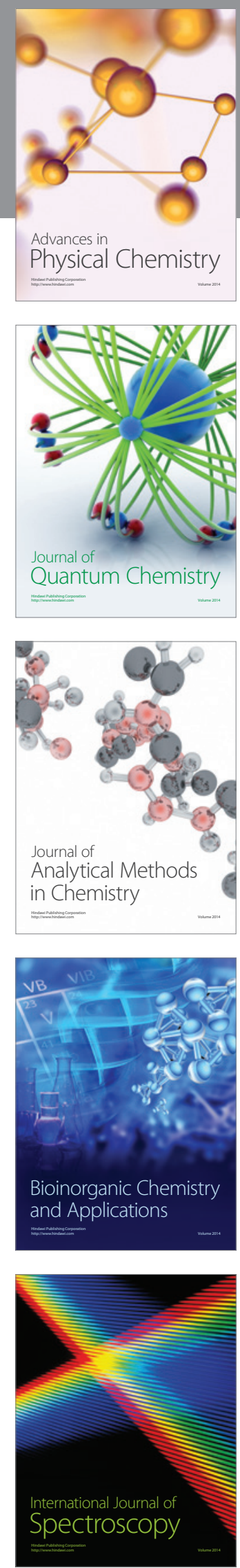